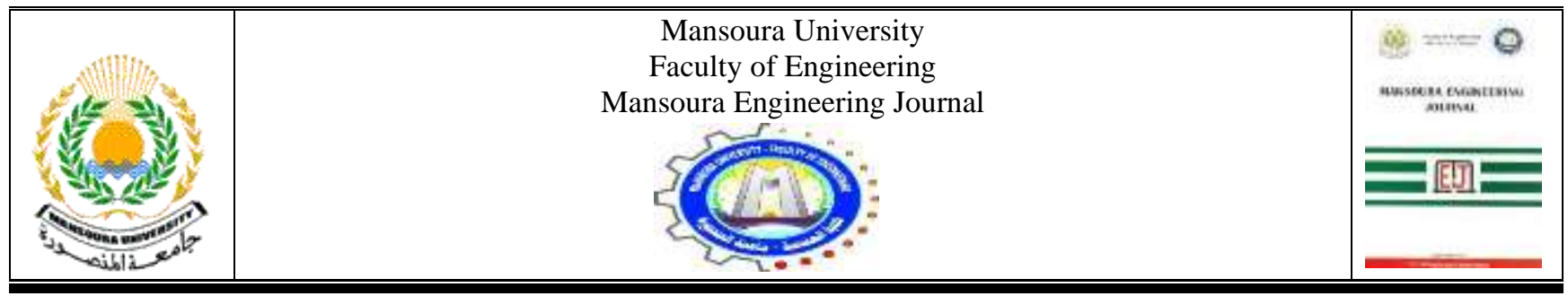

\title{
Confined Seepage underneath Hydraulic Structures Using Strong Form Differential Quadrature Element Method

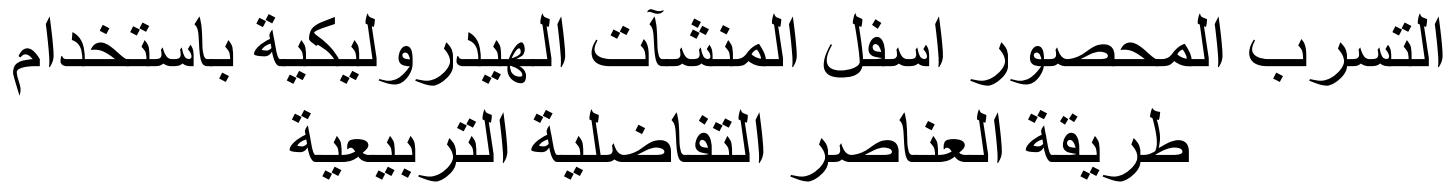

Aya Bakr, El-Masry A.A, Ali Masria And Hossam A.A. Abdelgawad

KEYWORDS:
Strong form differential
quadrature element
method.
-Confined seepage.
-Laplace equation.
-Concrete dam.
-Hydraulic structures.

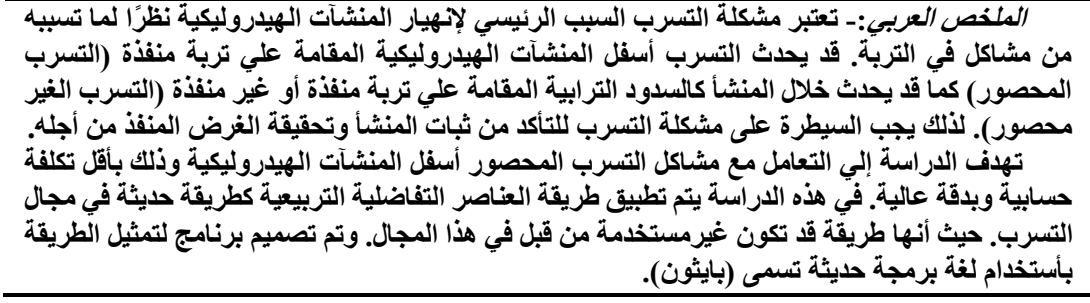

\begin{abstract}
Strong Form Differential Quadrature Element Method (DQEM) is a non-ubiquitous technique for solving various physical and engineering problems having arbitrary domain configurations and complicated boundary conditions. In the present paper, the DQEM is adopted to simulate 2D steady-state confined seepage using quadrilateral elements unprecedentedly. The method discretizes the studied domain to a number of homogenous isotropic or anisotropic zones/elements. Techniques for defining boundary conditions are presented. The numerical modeling process is implemented in a PYTHON computer code. Various problems are solved in the present paper and the obtained results are compared with the available results of theoretical and numerical methods pre-published in the literature. Numerical results demonstrate the rigor and eligibility of the unfamiliar approach (DQEM) with less computational efforts.
\end{abstract}

Received: (10 February, 2020) - - accepted: (20 May, 2020)

AYA BAKR is Teaching Assistant, Irrigation and Hydraulics Engineering Dept., Mansoura University, Mansoura 35516, Egypt (email: ayabakr999@mans.edu.eg).

El-MASRY A.A is Prof. of, Irrigation and Hydraulics Engineering Dept., Mansoura University, Mansoura 35516, Egypt (email:admasry@mans.edu.eg).

ALI MASRIA is Lecturer, Currently, at College of Engineering, Jouf University, Sakaka, Aljouf 2018, Kingdom of Saudi Arabia

\section{INTRODUCTION}

$\mathrm{I}$ $\mathrm{T}$ is well known that, seepage is considered the main reason causing the failure of dams and other hydraulic structures due to its potential to cause an internal eruption of soil [1]. It has a great influence on their stabilities and performances. Consequently, it is necessary to be controlled to stop concealed internal and external erosion of soil grains [2]. Seepage flow may occur beneath and through heading-up structures. Besides, it may occur through earth dams founded on impervious and/or previous soils. Consequently, many researchers have developed different analytical [3] and numerical methods to investigate seepage such as the finite difference method (FDM), [4], to analyze seepage problems.

(email:aatef@ju.edu.sa). Irrigation and Hydraulics Engineering Dept., Mansoura University, Mansoura 35516, Egypt (email:ali_maaasria@mans.edu.eg)

HOSSAM A.A. ABDELGAWAD is Associate Prof. of, Irrigation and Hydraulics Engineering Dept., Mansoura University, Mansoura 35516, Egypt (email:hossamaaa@mans.edu.eg). 
The Crank Nicolson form of the FDM is used to determine seepage velocity and total seepage flow under a dam [5].

The boundary element method (BEM) is used to study characteristics of seepage underneath heading-up structures [6]. Confined and unconfined unsteady seepage problems in anisotropic and nonhomogeneous materials using the combination of the finite element method (FEM) and BEM are investigated [7]. There are two approaches of DQEM, which based on weak formulation finite element method (WFEM) [8] and another based on strong formulation finite element method (SFEM) [9], the most significant difference between both approaches relies on the formulation of solving the parent element. The integral quadrature has to be used in the WFEM to solve the problem while the differential quadrature has to be used in SFEM. The weak form of the quadrature element method (QEM) has been applied to deal with two and three dimensional confined and unconfined seepage analysis through dams, and to obtain the location of free surface seepage line through dams [10], and [11], respectively. As well as solving hydraulics problems [12], and [13]. The strong form QEM has been applied in different applications to solve problems of structural mechanics with discontinuously distributed loads with multiple boundary conditions, and analyze slender members and axisymmetric plates and to deal with arbitrary geometries [14], [15], and [16] ; likewise, it has the ability to deal with heat transfer and torsion problems governed by Laplace and Poisson equation [17], and [18]. Effect of cut off position and inclination is studied under heading-up structures using DQEM [19]. In this paper, the strong form DQEM [9] is applied to deal with 2D steady-state confined seepage problems governed by Laplace equation only recently. DQEM almost has the same feature of SFEM as well as it uses the differential quadrature (DQ) rule to compute the weighting coefficients. Consequently, it combines the merits of both DQ and SFEM [20]; attaining the feasibility and high accuracy which enable it to deal with two and three- dimensional problems [21], and [11]. Through DQEM approach, the concept of SFEM is applied as well as DQ is utilized for the discretization of equations by dividing the whole physical domain into various subdomains/zones (quadrature elements), and generic transformation is used to map physical domain onto the normalized domain [22]. Thereafter, the DQ formulation is applied to compute weighting coefficients for the typical grid points distributions used and the governing equations are utilized at all inner points [23]. Moreover, the element connectivity is performed by applying the continuity equations at neighborhood boundaries of the quadrature elements and the boundary conditions (Dirichlit and Neumann) are applied at other sides of the quadrature element [18].

The numerical algorithm is executed into a computer code, and different examples are solved using the present method. Numerical results show the high efficiency and accuracy of the uncommon approach DQEM with less computational efforts.

\section{GOVERNING EQUATION}

The differential equation of 2D steady-state potential seepage problem is subjected to Laplace equation which describes the energy loss associated with flow through soil [23]:

$$
k_{x} \frac{\partial^{2} \mathrm{~h}}{\partial x^{2}}+k_{y} \frac{\partial^{2} \mathrm{~h}}{\partial y^{2}}=0
$$

where:

$k_{x, y}$ : Hydraulic conductivity of soil at $\mathrm{x}$ and $\mathrm{y}$

direction $\left(\mathrm{m} \mathrm{s}^{-1}\right)$.

h: Hydraulic head of flow (m).

$\mathrm{x}, \mathrm{y}$ : Coordinates of the studied point (m).

The general equation of boundary condition is,

$$
\mathrm{C}_{1} h+\mathrm{C}_{2} \frac{\partial h}{\partial n}=\text { constant }
$$

From Eqn. (2) for $C_{2}=0$ the boundary condition will be Dirichlit type, while for $C_{1}=0$ the boundary condition will be Neumann type.

\section{TRANSFORMATION FORMULATION}

General transformation is obtained to map the physical domain $(\mathrm{x}, \mathrm{y})$ into the master normalized domain $(\xi, \mu)$ (Fig. 1), [21].

where:

$$
\left\{\begin{array}{l}
x=x(\xi, \mu) \\
y=y(\xi, \mu)
\end{array}\right.
$$

$-1 \leq(\xi, \mu) \leq 1$

From the Jacobin matrix of the transformation, the following relations can be obtained:

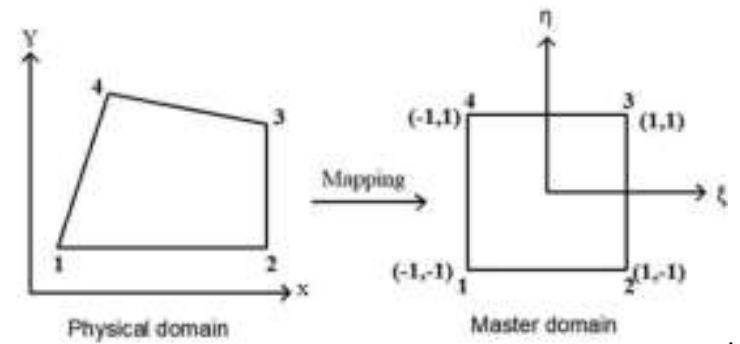

Fig. 1. Mapping of a linear quadrilateral element

$$
\begin{aligned}
& \frac{\partial h}{\partial x}=\frac{\partial h}{\partial \xi} \frac{\partial \xi}{\partial x}+\frac{\partial h}{\partial \mu} \frac{\partial \mu}{\partial x} \\
& \frac{\partial h}{\partial y}=\frac{\partial h}{\partial \xi} \frac{\partial \xi}{\partial y}+\frac{\partial h}{\partial \mu} \frac{\partial \mu}{\partial y}
\end{aligned}
$$

Further, the second-order partial derivative of $\mathrm{x}$ is as follows:

$$
\begin{aligned}
\frac{\partial^{2} h}{\partial x^{2}}=\frac{\partial^{2} h}{\partial \xi^{2}}\left(\frac{\partial \xi}{\partial x}\right)^{2} & +2 \frac{\partial^{2} h}{\partial \xi \partial \mu} \frac{\partial \mu}{\partial x} \frac{\partial \xi}{\partial x}+\frac{\partial^{2} h}{\partial \mu^{2}}\left(\frac{\partial \mu}{\partial x}\right)^{2} \\
& +\frac{\partial^{2} \xi}{\partial x^{2}} \frac{\partial h}{\partial \xi}+\frac{\partial^{2} \mu}{\partial x^{2}} \frac{\partial h}{\partial \mu}
\end{aligned}
$$

Similarly, the second-order partial derivative concerning variable $y$ is obtained as: 


$$
\begin{aligned}
\frac{\partial^{2} h}{\partial y^{2}}=\frac{\partial^{2} h}{\partial \xi^{2}}\left(\frac{\partial \xi}{\partial y}\right)^{2} & +2 \frac{\partial^{2} h}{\partial \xi \partial \mu} \frac{\partial \mu}{\partial y} \frac{\partial \xi}{\partial y} \\
& +\frac{\partial^{2} h}{\partial \mu^{2}}\left(\frac{\partial \mu}{\partial y}\right)^{2}+\frac{\partial^{2} \xi}{\partial y^{2}} \frac{\partial h}{\partial \xi} \\
& +\frac{\partial^{2} \mu}{\partial y^{2}} \frac{\partial h}{\partial \mu}
\end{aligned}
$$

The first and second-order derivative of $\xi$ and $\mu$ concerning $\mathrm{x}$ and $\mathrm{y}$ can be demonstrated as:

$$
\begin{array}{ll}
\frac{\partial \xi}{\partial x}=\frac{\partial y}{\partial \mu}|J|^{-1} & \frac{\partial \xi}{\partial y}=\frac{-\partial x}{\partial \mu}|J|^{-1} \\
\frac{\partial \mu}{\partial x}=\frac{-\partial y}{\partial \xi}|J|^{-1} & \frac{\partial \mu}{\partial y}=\frac{\partial x}{\partial \xi}|J|^{-1}
\end{array}
$$

Using (3) and (4), the following second-order derivatives of the master normalized domain $(\xi, \mu)$ concerning to the physical domain $(\mathrm{x}, \mathrm{y})$ can be obtained as,

$$
\begin{aligned}
& \frac{\partial^{2} \xi}{\partial x^{2}}=\frac{\partial y}{\partial \mu}|J|^{-2}\left[\left(1-\left(\frac{\partial x}{\partial \xi} \frac{\partial y}{\partial \mu}+\right.\right.\right. \\
& \left.\left.\left.\frac{\partial y}{\partial \xi} \frac{\partial x}{\partial \mu}\right)|J|^{-1}\right) \frac{\partial^{2} y}{\partial \xi \partial \mu}+\left(2 \frac{\partial y}{\partial \xi} \frac{\partial y}{\partial \mu}\right)|J|^{-1} \frac{\partial^{2} x}{\partial \xi \partial \mu}\right] \\
& \frac{\partial^{2} \xi}{\partial y^{2}}=\frac{\partial x}{\partial \mu}|J|^{-2}\left[\left(1+\left(\frac{\partial x}{\partial \xi} \frac{\partial y}{\partial \mu}+\right.\right.\right. \\
& \left.\left.\left.\frac{\partial y}{\partial \xi} \frac{\partial x}{\partial \mu}\right)|J|^{-1}\right) \frac{\partial^{2} x}{\partial \xi \partial \mu}-\left(2 \frac{\partial x}{\partial \xi} \frac{\partial x}{\partial \mu}\right)|J|^{-1} \frac{\partial^{2} y}{\partial \xi \partial \mu}\right]
\end{aligned}
$$

Similarly,

$$
\begin{aligned}
& \frac{\partial^{2} \mu}{\partial x^{2}}=\frac{\partial y}{\partial \xi}|J|^{-2}\left[\left(1+\left(\frac{\partial x}{\partial \xi} \frac{\partial y}{\partial \mu}+\right.\right.\right. \\
& \left.\left.\left.\frac{\partial y}{\partial \xi} \frac{\partial x}{\partial \mu}\right)|J|^{-1}\right) \frac{\partial^{2} y}{\partial \xi \partial \mu}-\left(2 \frac{\partial y}{\partial \xi} \frac{\partial y}{\partial \mu}\right)|J|^{-1} \frac{\partial^{2} x}{\partial \xi \partial \mu}\right] \\
& \frac{\partial^{2} \mu}{\partial y^{2}}=\frac{\partial x}{\partial \xi}|J|^{-2}\left[\left(1-\left(\frac{\partial x}{\partial \xi} \frac{\partial y}{\partial \mu}+\right.\right.\right. \\
& \left.\left.\frac{\partial y}{\partial \xi} \frac{\partial x}{\partial \mu}\right)|J|^{-1}\right) \frac{\partial^{2} x}{\partial \xi \partial \mu}+ \\
& \left.\left(2 \frac{\partial x}{\partial \xi} \frac{\partial x}{\partial \mu}\right)|J|^{-1} \frac{\partial^{2} y}{\partial \xi \partial \mu}\right]
\end{aligned}
$$

\section{A QUADRILATERAL ELEMENT FORMULATION}

The mapping transformation relations of the quadrilateral physical domain with global coordinates $(\mathrm{x}, \mathrm{y})$ into the master normalized domain with natural coordinates $(\xi, \mu)$, (Fig. 1) are expressed as follow, by substitution of equations (5) and (6) into (1), results in [21]:

$$
\begin{aligned}
F_{1}(\xi, \mu) \frac{\partial^{2} h}{\partial \xi^{2}}+F_{2} & (\xi, \mu) \frac{\partial^{2} h}{\partial \xi \partial \mu}+F_{3}(\xi, \mu) \frac{\partial^{2} h}{\partial \mu^{2}} \\
& +F_{4}(\xi, \mu) \frac{\partial h}{\partial \xi}+F_{5}(\xi, \mu) \frac{\partial h}{\partial \mu} \\
& =0
\end{aligned}
$$

where:

$$
\begin{aligned}
& F_{1}(\xi, \mu)=k_{x}\left(\frac{\partial \xi}{\partial x}\right)^{2}+k_{y}\left(\frac{\partial \xi}{\partial y}\right)^{2} \\
& F_{2}(\xi, \mu)=2\left(k_{x} \frac{\partial \xi}{\partial x} \frac{\partial \mu}{\partial x}+k_{y} \frac{\partial \xi}{\partial y} \frac{\partial \mu}{\partial y}\right) \\
& F_{3}(\xi, \mu)=k_{x}\left(\frac{\partial \mu}{\partial x}\right)^{2}+k_{y}\left(\frac{\partial \mu}{\partial y}\right)^{2}
\end{aligned}
$$

$$
\begin{aligned}
& F_{4}(\xi, \mu)=k_{x} \frac{\partial^{2} \xi}{\partial x^{2}}+k_{y} \frac{\partial^{2} \xi}{\partial y^{2}} \\
& F_{5}(\xi, \mu)=k_{x} \frac{\partial^{2} \mu}{\partial x^{2}}+k_{y} \frac{\partial^{2} \mu}{\partial y^{2}}
\end{aligned}
$$

\section{DisCRETIZATION OF DQ}

The discretization of the differential quadrature approximation on (12) leads up to the following equation

$$
\begin{aligned}
F_{1} \sum_{n=1}^{N_{\xi}} W_{i n}{ }^{(2)} h_{n j} & +F_{2} \sum_{m_{m=1}^{N_{\mu}}}^{N_{\mu}} W_{j m}{ }^{(1)} \sum_{n=1}^{N_{\xi}} W_{i n}{ }^{(1)} h_{n m} \\
& +F_{3} \sum_{\substack{m_{=1} \\
N_{\xi}}} W_{j m}{ }^{(2)} h_{i m} \\
& +F_{4} \sum_{n=1}^{N_{\mu}} W_{i n}{ }^{(1)} h_{n j} \\
& +F_{5} \sum_{m=1}^{N_{j m}{ }^{(1)} h_{i m}=0}
\end{aligned}
$$

where:

$$
\left(\mathrm{i}=2,3,4 \ldots \ldots, N_{\xi}-1 ; \mathrm{j}=2,3,4 \ldots \ldots, N_{\mu}-1\right)
$$

$W_{i j}{ }^{(k)}=$ The weighting coefficients of DQ attached to the function values

$(k)=$ Derivative degree of the function

$N_{\xi}=$ Number of nodes in $\xi$ direction

$N_{\mu} \quad=$ Number of nodes in $\mu$ direction

The weighting coefficients are based on the Lagrange interpolation formula. The weighting coefficients in the $(\xi)$ direction are as follows [22]:

$$
\begin{aligned}
& W_{i j}^{(1)}=\left\{\begin{array}{l}
\frac{M^{(1)}\left(\xi_{i}\right)}{\left(\xi_{i}-\xi_{j}\right) M^{(1)}\left(\xi_{j}\right)}, i \neq j \\
-\sum_{n=1, n \neq i}^{N} W_{i n}^{(1)}, i=j
\end{array}\right. \\
& W_{i j}^{(k)}=\left\{\begin{array}{c}
k\left[W i i^{(k-1)} W_{i j}^{(1)}-\frac{W i j^{(k-1)}}{\left(\xi_{i}-\xi_{j}\right)}\right], i \neq j \\
-\sum_{n=1, n \neq i}^{N} W_{i n}{ }^{(m)}, i=j
\end{array}\right.
\end{aligned}
$$

where:

$$
\left\{\begin{array}{c}
M(\xi)=\prod_{j=1}^{N}\left(\xi-\xi_{j}\right) \\
M^{(1)}\left(\xi_{n}\right)=\prod_{j=1, j \neq n}^{N}\left(\xi_{n}-\xi_{j}\right), n=1,2,3, \ldots, N
\end{array}\right.
$$

The formulas of weighting coefficients in the $(\mu)$ direction are identical to the $(\xi)$ direction. 
The governing equations are utilized at all inner points. The continuity equations are applied at common boundaries of quadrature elements and the boundary conditions are applied at other sides of the quadrature element.

\section{BOUNDARY CONDITIONS}

\section{A)Interior boundary condition}

The common boundary of two adjacent elements DC is shown in Fig. 2 is subjected to the continuity equation (17), and (18).

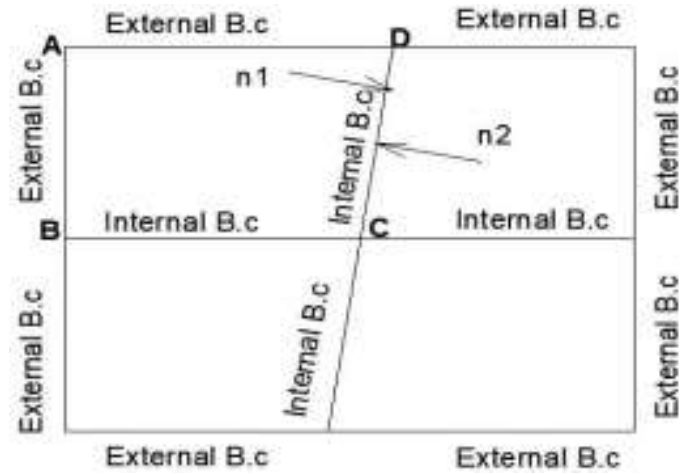

Fig. 2. Constraint boundary conditions for a considered domain.

$$
\begin{gathered}
\left.\frac{\partial h^{(1)}}{\partial n_{1}}\right|_{D C}=-\left.\frac{\partial h^{(2)}}{\partial n_{2}}\right|_{D C} \\
\frac{\partial h}{\partial n_{i}}=\left(k_{x} l \frac{\partial \xi}{\partial x}+k_{y} m \frac{\partial \xi}{\partial y}\right) \frac{\partial h}{\partial \xi} \\
+\left(k_{x} l \frac{\partial \mu}{\partial x}+k_{y} m \frac{\partial \mu}{\partial y}\right) \frac{\partial h}{\partial \mu}
\end{gathered}
$$

It is essential to determine direction cosines $l$ and $m$ of the outward unit normal vector for boundary conditions of the element [18].

\section{B)Exterior boundary condition}

When derivative appears in boundary conditions, the transformation should be obtained as discussed before (2).

\section{C) Boundary conditions at quadrature element corners}

Generally, there are three constraint boundary conditions for the quadrature element corner depending on the relations between the element corners and element sides. In Fig. 2, on the corner node (A) one of the two external boundary conditions on $(\mathrm{AB}$ or $\mathrm{AD})$ can be applied. If the Dirichlet type boundary condition exists, it has priority to be considered as it gives the exact value of the dependent variable at the studied node. One of the two external boundary conditions or the internal boundary condition can be prescribed on nodes (D) and (B).

\begin{tabular}{|c|c|c|c|c|c|c|c|c|c|}
\hline \multirow[b]{2}{*}{$\mathrm{x} / \mathrm{b}$} & \multicolumn{9}{|c|}{ COMPARISON BETWEEN THEORETICAL METHOD, FEM, AND DQEM (RELATIVE ERROR) } \\
\hline & -1 & -0.75 & -0.5 & -0.25 & 0 & 0.25 & 0.5 & 0.75 & 1 \\
\hline Theoretically & 1.0000 & 0.7699 & 0.6666 & 0.5804 & 0.5000 & 0.4195 & 0.3333 & 0.2300 & 0.0000 \\
\hline FEM (489nodes) & 1.0000 & 0.7968 & 0.6831 & 0.5886 & 0.5001 & 0.4115 & 0.3169 & 0.2036 & 0.0000 \\
\hline Relative error\% & $0 \%$ & $-3.49 \%$ & $-2.47 \%$ & $-1.41 \%$ & $0 \%$ & $1.90 \%$ & $4.92 \%$ & $11.48 \%$ & $0 \%$ \\
\hline DQEM (207nodes) & 1.0000 & 0.7603 & 0.6642 & 0.5798 & 0.5000 & 0.4202 & 0.3358 & 0.2390 & 0.0000 \\
\hline Relative error\% & $0 \%$ & $1.24 \%$ & $0.36 \%$ & $0.10 \%$ & $0 \%$ & $-0.16 \%$ & $-0.75 \%$ & $-3.91 \%$ & $0 \%$ \\
\hline
\end{tabular}
The corner node $(\mathrm{C})$ is an internal node of the quadrature

TABLE I elements that connects more than two elements by internal boundaries, so only one continuity equation on the four sides can be specified.

\section{NUMERICAL RESULTS}

Different problems are solved using DQEM. Comparisons between different numerical and theoretical methods have been done.

\section{1) Seepage flow under a single floor based on permeable soil}

The geometry of the problem shown in Fig. 3, for upstream and downstream beds is represented to a limited domain of $(\mathrm{L} / 2 \mathrm{~b}=\mathrm{T} / 2 \mathrm{~b}=1.0)$, and $\mathrm{H}=1.0 \mathrm{~m}$. This problem previously solved theoretically by Pavlvosky [24], also re-solved in the present work using the FEM with 363 triangular elements and a total 489 nodes. The Geo-studio software [24] was adopted to use the FEM. Concerning our new developed approach, the problem is computed using DQEM with 3-quadrilateral elements $(9 \times 9)$ uniform grid points with a total of 207 nodes. The applied boundary conditions shown in Fig. 4 are Neumann condition $\frac{\partial h}{\partial n}=0$ for boundaries 1 and 2, continuity equation for boundaries 3, Dirichlit conditions $h=1.0$ for boundary 4, and $h=0$ for boundary 5. The values of the coefficient of permeability are $k_{x}=k_{y}=1 \mathrm{~m} /$ day. The computed uplift pressure heads are shown in Fig. 5.

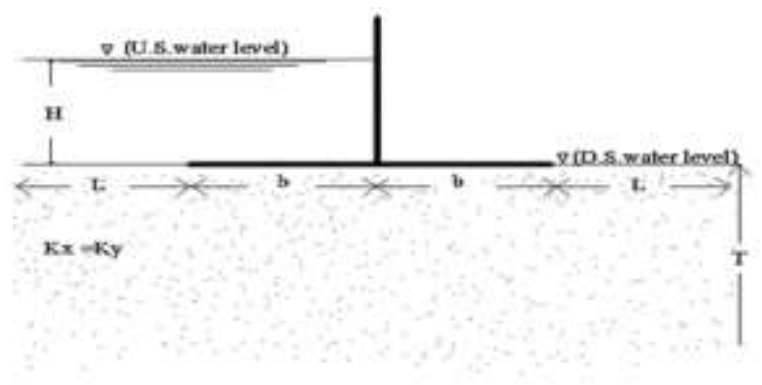

Fig. 3. Seepage flow under weir with a single floor.

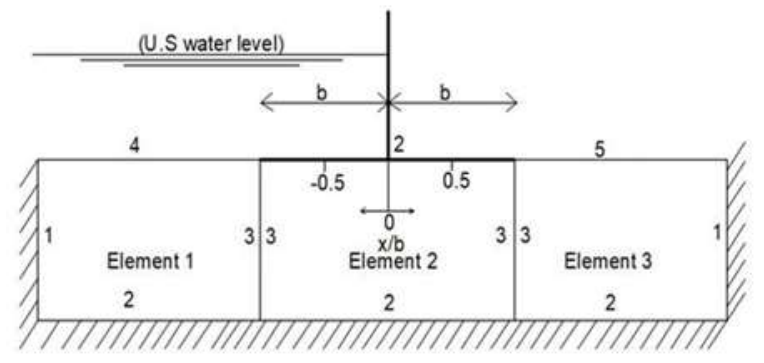

Fig. 4. Applied boundary conditions 


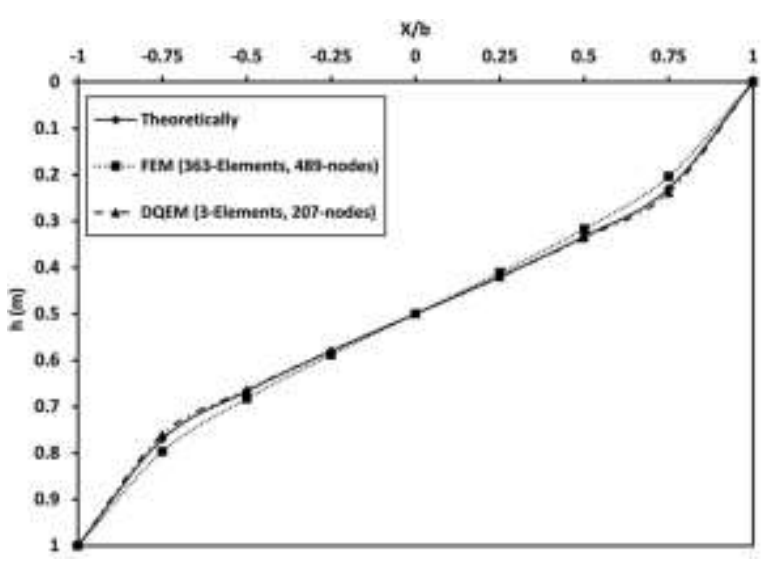

Fig. 5. Uplift pressure heads vs. $\mathrm{x} / \mathrm{b}$ under the floor.

Comparing the results of DQEM with theoretical results and FEM results under-floor in Table $\mathrm{I}$, it is noticed that, using (DQEM) using only 3-quadrilateral elements with 207 nodes reduces the error by $66 \%$ of the corresponding error by FEM using 363 triangular elements with 489 nodes. So, it is concluded that, the (DQEM) results substantiate the high precision and competence of (DQEM) with a few number of unknown.

\section{2) Seepage flow under a depressed structure on an infinite} permeable depth

The geometrical characteristics of the problem shown in Fig. 6 are represented to a limited domain of $2 \mathrm{~L}=40 \mathrm{~m}$ and $(T=$ $\mathrm{b}=80 \mathrm{~m})$. The problem is computed using DQEM with 5quadrilateral elements (Fig. 7) using different grid points within each element (Fig. 8). This problem has been solved previously in analytical way by [24]. The convergence by increasing discrete points in an element is shown in Fig. 8.

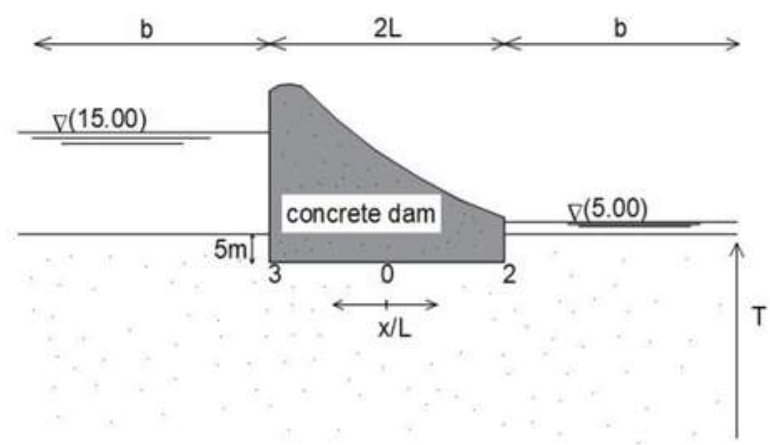

Fig. 6. A depressed structure on a permeable soil with an infinite depth.

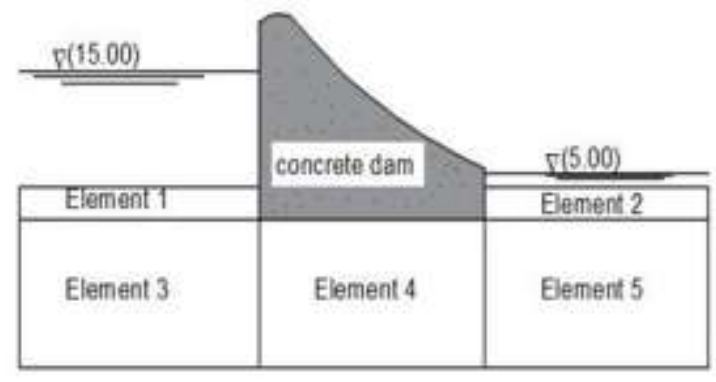

Fig. 7. Elements represent the studied domain

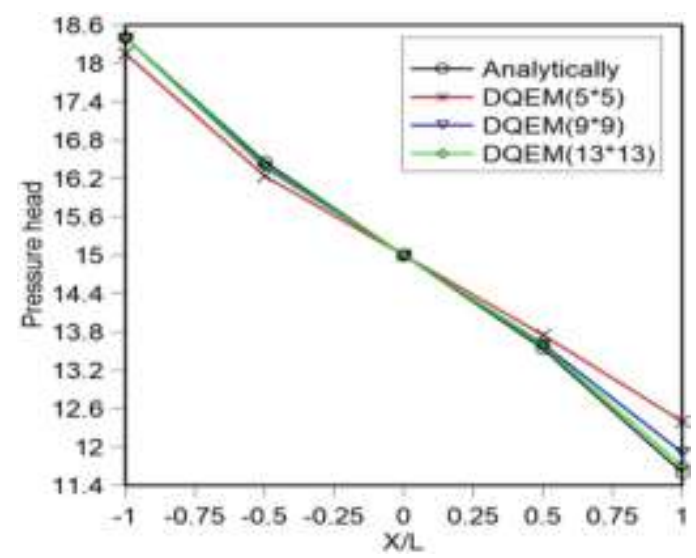

Fig. 8. Convergence by increasing by discrete points in an element.

The numerical results demonstrate high accuracy and the efficiency of DQEM. They also have an acceptable convergence by increasing discrete points in an element (Fig. $8)$.

3) Seepage under an irregular concrete dam based on Homogeneous and isotropic soil

Seepage under an irregular concrete dam based on homogeneous and isotropic soil is considered as shown in Fig. 9, was previously solved using the FEM and Scaled-Boundary Finite Element Method (SBFEM), [7] using 4288 and 104 nodes, respectively. The same problem was solved by the Scaled-Boundary Radial Point Interpolation Method (SBRPIM), [26] using 102 nodes in case of unsteady flow at various time steps. In the present paper, DQEM is used to solve this example using 95 nodes (Fig. 10). The comparisons are obtained between the results of DQEM and the results of FEM, SBFEM, and SBRPIM, at time step 0 (Fig. 11)

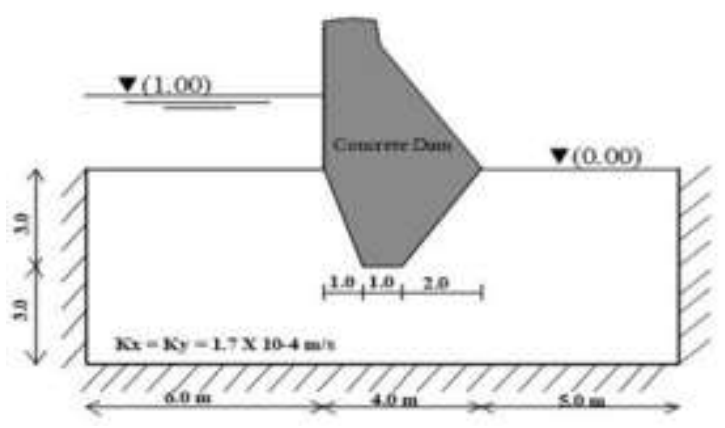

Fig. 9. Seepage flow under an irregular concrete dam based on homogeneous and an isotropic soil 


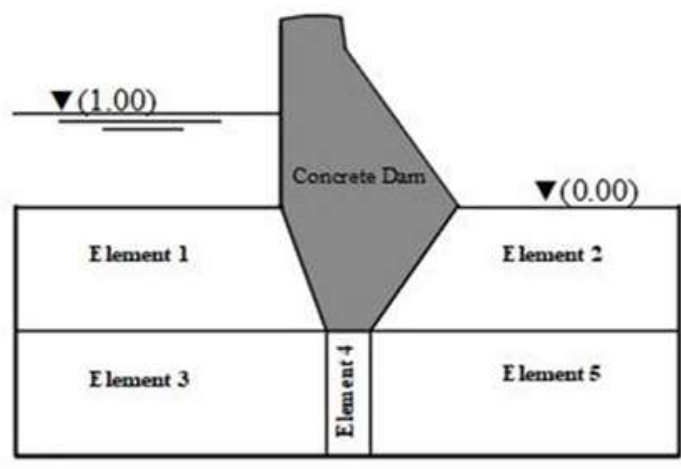

Fig. 10. (DQEM) domain divided into (5-quadrilateral elements) $5 \times 5$ uniform grid points.

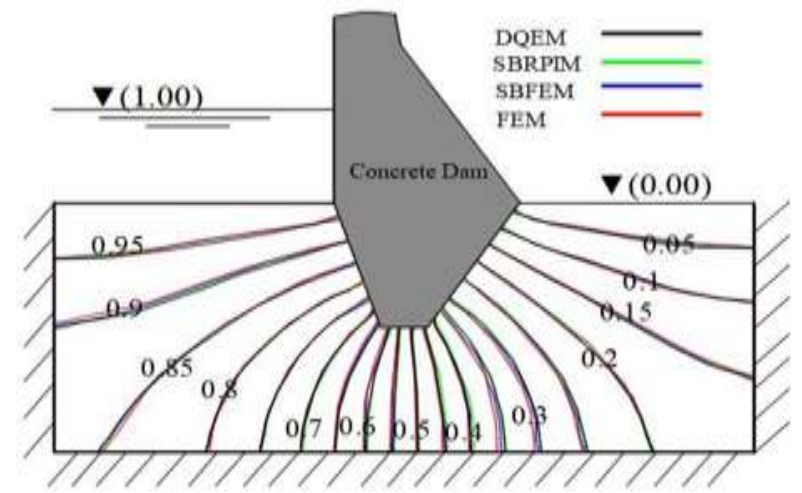

Fig. 11. Equipotential lines under the irregular concrete dam

It can be observed that there is good agreement between the results of DQEM and FEM, SBFEM, and SBRPIM which demonstrate the accuracy of DQEM as well as cost-saving by using a number of nodes much less than other numerical methods.

\section{CONCLUSION}

In this paper, the strong form DQEM 2D steady-state confined seepage has been proposed unprecedentedly. The mapping technique was used to develop the irregular elements which can be used to resolve problems having irregular domain configurations. Handling constraint conditions were elucidated with different techniques. The unfamiliar approach solves various examples of steady-state confined seepage under hydraulic structures. Numerical outcomes demonstrated that the strong form DQEM is a good numerical alternative as accurate results can be obtained with much less degree of freedom.

\section{REFERENCES}

[1] Okeke, A.C.-U., Wang, F. (2016). "Critical hydraulic gradients for seepage-induced failure of landslide dams". Geoenvironmental Disasters. vol .3, no. 1, pp.1-22. https://doi.org/10.1186/s40677-016-0043-z.

[2] Xiang, Y., Fu, S. Yan, Zhu, K., Yuan, H., Fang, Z. Yuan (2017). "Seepage safety monitoring model for an earth rock dam under influence of highimpact typhoons based on particle swarm optimization algorithm". Water Sci. Eng. vol. 10, pp.70-77. https://doi.org/10.1016/j.wse.2017.03.005.

[3] Mohsenian, A.-R., Sedghi-Asl, M., Rahimi, H. (2019). "An analytical solution for confined seepage problem beneath hydraulic structures". Iran. J. Sci. Technol. Trans. Civ. Eng. vol. 43, no. 2, pp.361-369. https://doi.org/10.1007/s40996-018-0146-8.
[4] Fukuchi, T. (2016). "Numerical analyses of steady-state seepage problems using the interpolation finite difference method". Soils Found. vol.56, no. 4, pp. 608-626. https://doi.org/10.1016/j.sandf.2016.07.003.

[5] Kiplangat Vincent, K., Nicholas Muthama, M., Nicodemus Muoki, S. (2014). "Darcy's Law equation with application to underground seepage in earth dams in calculation of the amount of seepage". Am. J. Appl. Math. Stat. vol. 2, no. 3, pp.143-149. https://doi.org/10.12691/ajams-2-3-8.

[6] El-Masry, A.A., Abd-Alla, M.G. (2003). "Charactristics of seepage underneath a Heading-Up Structura and Subsidiary one". Mansoura Eng. $\begin{array}{llll}\text { J. } & \text { vol. } & \text { 28, } & \text { 32-46. }\end{array}$ https://doi.org/https://search.emarefa.net/detail/BIM-368731.

[7] Bazyar, M.H., Talebi, A. (2014). "Transient seepage analysis in zoned anisotropic soils based on the scaled boundary finite-element method". Int. J. Numer. Anal. Methods Geomech. vol.39, no. 1, pp.1-22. https://doi.org/10.1002/nag.2291.

[8] Chen, C.-N. (2000). "A generalized differential quadrature element method". Comput. Methods Appl. Mech. Eng. vol.188, pp. 553-566. https://doi.org/10.1016/S0045-7825(99)00283-2.

[9] Tornabene, F., Fantuzzi, N., Ubertini, F., Viola, E. (2015). "Strong formulation finite element method based on differential quadrature". A Survey. Appl. Mech. Rev. vol. 67, no. 2, pp. 020801. https://doi.org/10.1115/1.4028859.

[10] Shuai, Y., Hong-zhi, Z. (2015). "Seepage analysis using the weak form quadrature element method ". Yantu Gongcheng Xuebao/Chinese Journal of Geotechnical Engineering, vol. 37, no. 2, pp. 257-262 https://doi.org/10.11779/CJGE201502007.

[11] Yuan, S., Zhong, H. (2016). "Three dimensional analysis of unconfined seepage in earth dams by the weak form quadrature element method". J. Hydrol. vol. 533, pp. 403-411. https://doi.org/10.1016/j.jhydrol.2015.12.034.

[12] Nikzad, J., Eslamian, S.S., Soleymannejad, M., Karimpour, A. (2016). "Numerical solution for one-dimensional Richards ' equation using differential quadrature method ". Current Science vol. 111, no. 6, pp. 1028-1036. https://doi.org/10.18520/cs/v111/i6/1028-1036.

[13] Salah, M., Amer, R.M., Matbuly, M.S. (2014). "The differential quadrature solution of reaction-diffusion equation using explicit and implicit numerical schemes". Applied Mathematics, vol. 5, no.3, pp. 327336. https://doi.org/http://dx.doi.org/10.4236/am.2014.53033.

[14] Zhong, H., Gao, M. (2007). "Transverse vibration analysis of an arbitrarily-shaped membrane by the weak-form quadrature element method". Computational Mechanics, Vol. 3, no. 81, pp. 377-387. https://doi.org/10.1007/978-3-540-75999-7_177.

[15] Xing, Y., Liu, B. (2009). "High-accuracy differential quadrature finite element method and its application to free vibrations of thin plate with curvilinear domain". Int. J. Numer. Methods Eng. vol. 80, pp. 1718-1742. https://doi.org/10.1002/nme.2685.

[16] Zhong, H., Yu, T. (2009). "A weak form quadrature element method for plane elasticity problems". Appl. Math. Model. vol.33, pp. 3801-3814. https://doi.org/10.1016/j.apm.2008.12.007.

[17] Zhong, H., He, Y. (1998). " Solution of poisson and laplace euations by quadrelateral quadrature element". Int. J. Solid Struct. vol.35, pp. 28052819. https://doi.org/10.1016/S0020-7683(97)00277-1.

[18] Chen, C. (1999). "The development of irregular elements, for differential quadrature element method steady-state heat conduction analysis". Comput. Methods Appl. Mech. Eng. vol.170, pp.1-14. https://doi.org/10.1016/S0045-7825(98)00185-6.

[19] Bakr, A., Masria, A.,EL-Masry, A.A, Abdelgawad, H.A.A. (2019)."Effect of Cut off Position and Inclination on Seepage Characteristics under Heading-up Structure Using Differential Quadrature Element Method," IJSER. vol. 10, no. 11, pp. 541-548. https://www.researchgate.net/publication/337782591.

[20] Xing, Y., Liu, B., G. (2010). "A differential quadrature finite element method". Int. J. Appl. Mech. vol. 2, pp. 207-227. https://doi.org/10.1142/S1758825110000470.

[21] Chen, C.N. (2004). "DQEM and DQFDM irregular elements for analyses of 2-D heat conduction in orthotropic media". Appl. Math. Model. vol. 28, pp.617-638. https://doi.org/10.1016/j.apm.2003.10.015.

[22] Xing, Y., Liu, B., G. (2010). "A differential quadrature finite element method". Int. J. Appl. Mech. vol. 2, pp. 207-227. https://doi.org/10.1142/S1758825110000470.

[23] Chang shu (2000). "Differential Quadrature and its application in Engineering", 1st editio. ed. Springer-Verlag London Berlin Heidelberg in 2000. https://doi.org/10.1007/978-1-4471-0407-0. 
[24] Harr, M.E. (1963). "Groundwater and seepage". New York. Courier Corporation

https://books.google.com.eg/books/about/Groundwater_and_Seepage.ht $\mathrm{ml}$ ?id=S3vZ_e-40pMC\&redir_esc=y

[25] GEO-SLOPE International Ltd (2012). "Seepage modeling with SEEP / W". https://doi.org/http://www.geo-slope.com.

[26] Hajiazizi, M., Graili, A. (2018). "Efficient scaled-boundary radial point interpolation method for unsteady confined-seepage flow through nonhomogeneous and anisotropic soils". Int. J. Geomech. vol. 18, no. 6, pp. 1-14. https://doi.org/10.1061/(ASCE)GM.1943-5622.0001143. 